\title{
A young lady with ANA negative SLE and Secondary Anti Phospholipid Syndrome
}

\section{Richmond Ronald Gomes ${ }^{1}$, Deepankar Kumar Basak ${ }^{2}$, Kaniz Rah man ${ }^{3}$, Md. Rashidul Hasan}

${ }^{1}$ Associate Professor of Medicine, Ad-din Women's Medical College and Hospital, Dhaka

${ }^{2}$ Associate Consultant, Medicine, Square Hospitals Limited

${ }^{3}$ Assistant Profe ssor of Dermatology, Ad-din Women's Medical College and Hospital, Dhaka

${ }^{4}$ Associate Professor of Dermatology, US Bangla Medical College and Hospital, Narayangonj

\section{A R T I C L E I N F O}

Keywords:

Antinuclear antibody

Anti ribosomal $\mathrm{P}$ antibody

Systemic lupus erythematosus

Antiphospholi pid

Anti phospholipid syndrome

Corresponding author:

Richmond Ronald Gomes

E-mail address:

\section{rrichi.dmc.k56@gmail.com}

All authors have reviewed and approved the final version of the manuscript.

https://doi.org/10.37275/IJR.v12i2.154

\begin{abstract}
A B S T R A C T
Systemic lupus erythematosus (SLE) is a chronic, inflammatory, autoimmune, multisystem connective multi system connective tissue disease characterized by various autoantibodies to nuclear and cytoplasmic antigens and commonly affects the joints and a variety of organs due to an over activation of the body's immune system. There is wide heterogeneity in presentation of SLE patients, including lung, central nervous system, skin, kidney, and hematologic manifestations. The presence of antinuclear antibodies (ANA) in serum is generally considered a decisive diagnostic sign of SLE. However, a small subset of SLE patients who had the typical clinical features of SLE was reported to show persistently negative ANA tests. Our report describes a 24-yr-old female who presented with the clinical manifestations of SLE such as malar rash, photosensitivity, arthritis, oral ulcer, and proteinuria. The serum autoantibodies were all negative except anti ribosomal $\mathrm{P}$. She was also positive for lupus anticoagulantanticoagulant. She was treated with oral prednisolone, hydroxychloroquine with topical tacrolimus, and improved significantly. Three months after, repeat ANA, and anti-ds DNA showed persistent negativity, but lupus anticoagulant remained positive. This case suggests that ANA may not be required in the pathogenesis of SLE.
\end{abstract}

\section{Introduction}

Systemic lupus erythematosus (SLE) is a complex disease characterized by an autoantibody response to nuclear and cytoplasmic antigens. The autoantibody response is associated with the inflammatory cascades and end-organ damage in the kidney, skin, brain, and other organs. Especially in the kidney, immune-complex deposits of autoantibodies have been implicated as major pathogenic mediators ${ }^{1}$.

The diagnosis of SLE can be made by fulfilling the revised criteria of the American College of Rheumatology2. One of the laboratory hallmarks of SLE is the presence of antinuclear antibodies (ANA) in the serum3. On the other hand, a small subset of SLE patients with the typical clinical findings of SLE was reported to have persistently negative ANA test. These patients were designated as ANA-negative SLE, and their clinical picture was notable for the high incidence of photosensitive dermatitis and the low incidence of nephritis and neuropsychiatric manifestations4. ANA negative SLE was first introduced by Koller et al. with five cases with clinical feature similar to SLE5. Here we report a young lady who presented polyarthritis, which was complicated 
with photosensitive rash and oral ulcer and later diagnosed as ANAnegative SLE.

\section{Case Report}

A 24 years old pleasant, unmarried, service holder, muslim lady admitted into Ad din Women's Medical College and Hospital with the complaints of pain in the multiple joints of both upper and lower limbs for last two2 months involving mainly small joints of hands (picture 1) and feet, wrists, ankles. Joint involvement was symmetrical and nonmigratory. There was associated inactivity stiffness that lasted for more than an hour and relieved partially with activity and taking analgesics. Joint pain was associated with low-gradelow grade intermittent fever (max recorded temperature was $1000 \mathrm{~F})$, not associated with chills and rigor, and subsided after taking antipyreticanti pyretic. Joint pain was not associated with any redness or increased warmth of the joints. She also denied any low back pain, buttock or groin pain, sole pain or pain over the heel. There was also no $\mathrm{H} / \mathrm{O}$ sexual exposure, urethral discharge or bloody diarrhoea preceding the illness. No red eye, visual impairment, proximal muscle pain or stiffness, papulopustular or acne form or scaly skin lesions were present either. There was also no history of dry mouth or dry eye, loss of scalp hair, venous thrombosis, tightening of skins of body, dysphagia, heartburnheart burn, altered bowel habit or any history suggestive of Raynaud's phenomenon. She denied any anorexia, night sweat or weight loss. After about one month later she developed painless oral ulcers (picture 2). But there were no genital ulcers.
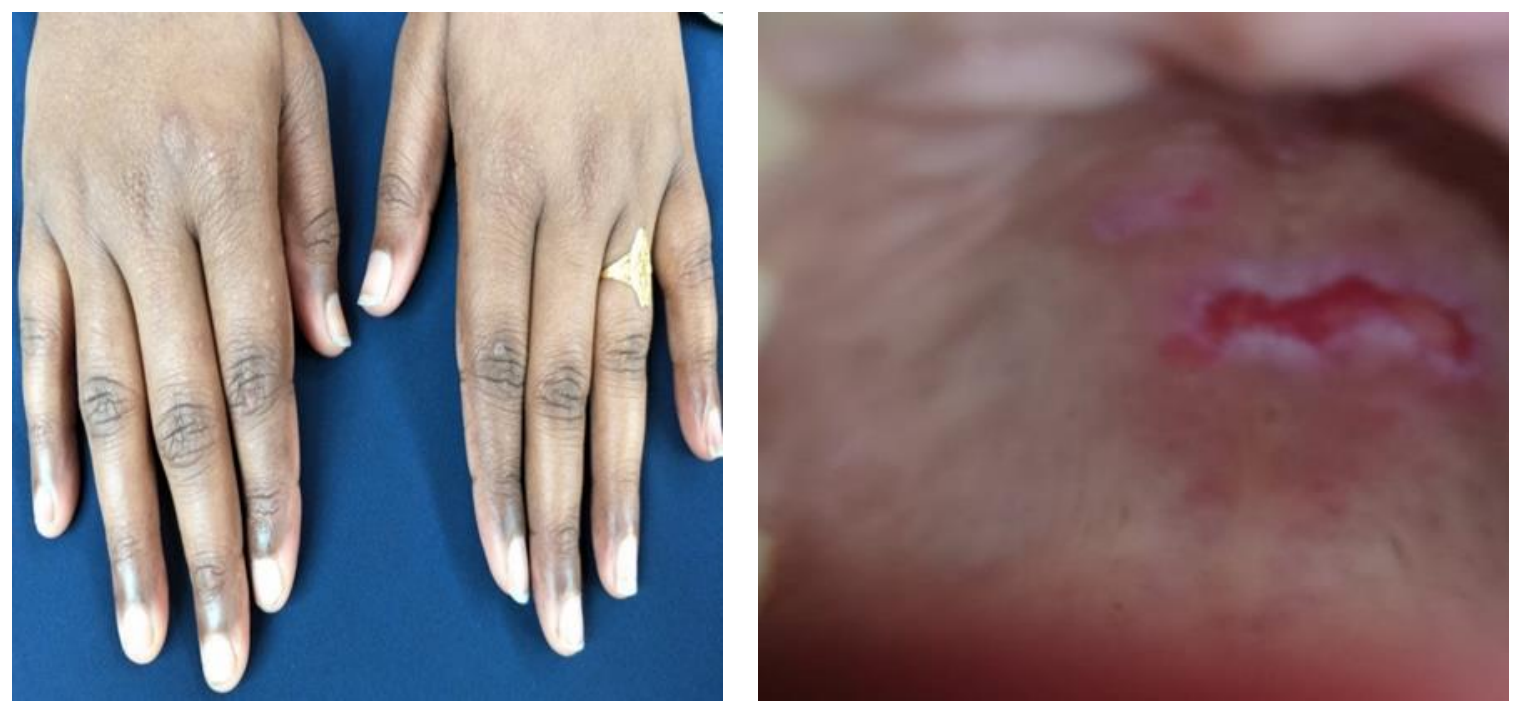

Picture 1:showing symmetrical arthritis involving MCP and PIP of both hands. Picture 2 showing an erythematous ulcer with irregular margin over hard palate.

At the same time she also developed erythematous, raised, painful, non-pruritic photosensitive rashes all over her face sparing the nasolabial folds (picture 3 and 4). But there were no bullous lesions or no crusts. 

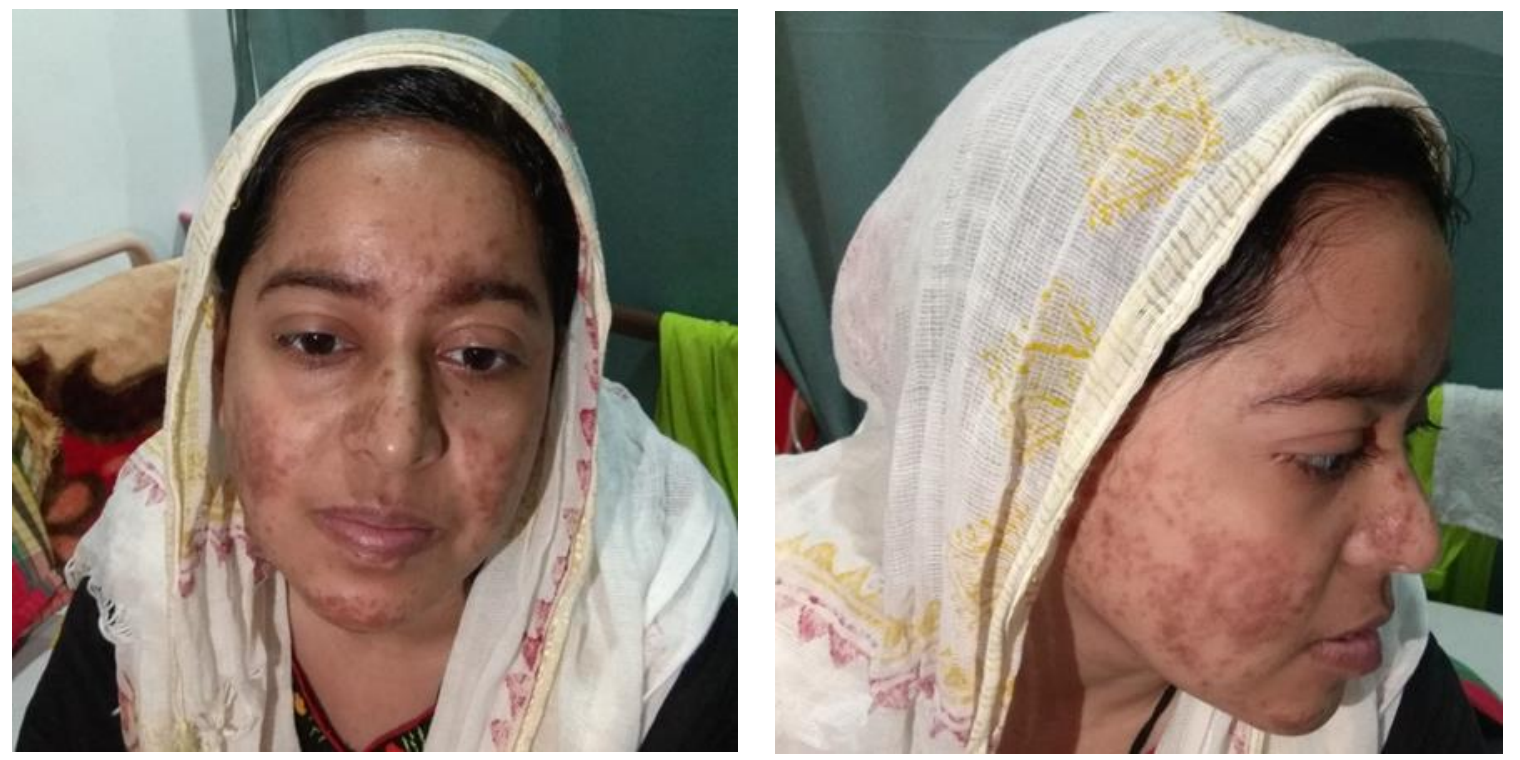

Picture3 \& 4 showing multiple, erythematous, raised rashes with no color change or no crusting all over the face sparing the nasolabial folds.

On further query, she stated that her paternal aunt had SLE. She had no significant drug history prior the illness except she took ceftriaxone for 7 days before admission. Her menstrual history was also noncontributory. She had neither any sexual promiscuity nor had any history of tuberculosis or any contact with the patient with active tuberculosis. On examination she was ill looking, febrile (temperature 1000 F) with stable vitals. She was moderately anemic but non-icteric and noncyanosed. There were erythematous, raised, tender rashes over both cheeks, forehead (sparing naso labial fold), there were some rashes over dorsum of hands and feet too. Skin was not thinned with nobruising or telangiectasia. Eyes including both fundi were normal, lymph nodes were not palpable, and thyroid gland was not enlarged. There was no edema, bony tenderness or any nail or peri-ungual vasculitic changes. On musculoskeletal system examination, GALS screening was done. Gait and spine examination revealed no abnormalities. On upper limb examination, MCP, PIP and wrists of both sides were swollen, tender and there was painful restriction of both active and passive movements of these joints. DIP's were spared. On lower limb examination, ankles and small joints of feet of both sides were swollen, tender and there was painful restriction of both active and passive movements of these joints. There were neither any deformities nor any evidences of sacroilitis or enthesitis. Oral cavity examination revealed painless ulcers with erythematous irregular margin over hard palate, right inner cheek. But there were no organomegaly. There were no evidences for serositis (ascites, pleural or pericardial effusion). Other systemic examination was noncontributory.

On investigation there was microcytic hypochromic anemia of $\mathrm{Hb}-7.92 \mathrm{gm} \%(\mathrm{MCV} 69$, $\mathrm{MCH}-22)$, ESR $60 \mathrm{~mm}$ in 1st hour, TC-1000/cmm(N38\%, L-54\%), TPC-1,60000/cmm, CRP. 58.5 $\mathrm{mg} / \mathrm{dl}, \mathrm{PBF}$ - microcytic hypochromic anemia with leucopenia and adequate platelets. Urine $\mathrm{R} / \mathrm{E}$ revealed; proteinuria (++), RBC- 15-20/HPF (nonmenstruating), granular cast 8-10/HPF. But there were no RBC or tubular cast. $\mathrm{S}$ albumin 31 gm/L, UTP- 1.01 gm/day, ALT- 74 U/L, S. ferritin 4035 ng/L. RFT, RBS, CPK, IgG, DCT, Blood C/S Urine $\mathrm{C} / \mathrm{S}$ all were noncontributory. On immunological test, ANA, Anti ds DNA, RA factor, Anti CCP all came negative.C4 was low $0.45 \mathrm{~g} / 1$. CXR P/A, Echocardiography, X- ray of both hands, USG of W/A revealed no abnormalities. Serological 
inve stigations for $\mathrm{HBV}$ and $\mathrm{HCV}$ were negative, VDRL non-reactive, anti cardiolipin antibody was negative but lupus anti-coagulant came positive. As there was still strong clinical suspicion of SLE, ENA profile was done and Po (RPP)60 or anti ribosomal P antibody came positive.

During hospital stay as patient developed high grade temperature, neutropenic sepsis was suspected and she was treated with combined piperacilin/ tazobactam and aminoglycoside along with isolation and neutropenic diet. 2 units of whole blood were transfused. Systemic steroid (oral prednisolone $1 \mathrm{mg} / \mathrm{kg} /$ day) with DMARD (hydroxychloroquine) was started with topical steroid and tacrolimus ointment .Regular monitoring of both hematological and biochemical parameters were done. On discharge, $\mathrm{Hb} \%-10.1 \mathrm{gm} / \mathrm{L}$, Total count$5200 / \mathrm{cmm}$ (PMN- 68\%,L- 30\%), ESR- $34 \mathrm{~mm}$ in 1sthr, TPC $-192000 / \mathrm{cmm}$, CRP- $4.92 \mathrm{mg} / \mathrm{dl}$, Urine R/E- no protein, no casts, no RBC, no WBC, S. Ferritin-243 $\mathrm{ng} / \mathrm{ml}$. After three weeks, on OPD follow up, tapering of systemic steroid was started, topical steroid and tacrolimus was stopped. She was advised to use sunscreen regularly. She was also explained about the course of the disease, treatment options, recognition of flares, and pregnancy outcome. Last but not the least, reassurance was given.

After three months, ANA, Anti ds DNA and lupus anti-coagulant were repeated. ANA and anti-ds DNA showed persistent negativity and lupus anticoagulant remained positive. So she was started low dose aspirin with hydroxychloroquine and tapering dose of steroid.

\section{Discussion}

Systemic lupus erythematosus is a chronic inflammatory autoimmune disease that involves many different organ systems, and this illness exhibits a wide spectrum of clinical manifestations. The diagnosis of SLE depends on the patient's clinical and laboratory abnormalities2. Various kinds of autoantibodies are present in the sera of SLE patients, and ANA is a diagnostic hallmark for SLE, having a frequency of $95 \%$ or greater in SLE patients6and its titre is one of the key diagnostic criteria for SLE. But ANA positivity is not mandatory for the diagnosis 7 . Sero-negativity in lupus patients may be due to technical failure or entrapment of ANA in circulating immune complexes.

The diagnosis of SLE can be made by combining clinical and laboratory findings but there is no criterion available at the moment for early identification of the disease. The 1997 American college of Rheumatology (ACR) criteria8 and its complimentary criteria; the 2012 systemic lupus international collaborating clinic (SLICC) criteria9 are designed for classification of SLE but not for the diagnosis. The 2012 SLICC criteria is very complex and it can be used when the ACR criteria cannot classify SLE.

However, several investigators have reported that small groups of patients with the clinical features of SLE have negative tests for ANA. These patients appear to represent $1-5 \%$ of the SLE population. The age of onset and the female predominance are the same for ANA-negative SLE as for ANA-positive SLE10. ANA-negative SLE patients are known to have a higher prevalence of anti-Ro antibody and cutaneous manifestations, as well as a lower prevalence of both central nervous system and renal involvement ${ }^{4,11}$. Maddison et al. described 66 SLE patients with negative ANA, as was determined by indirect immuno-fluorescence. They found serum antibodies to cytoplasmic components; $62 \%$ of patients had anti-Ro antibody and 27\% had anti-La antibody4.

One explanation for the ANA-negative finding is technical inaccuracy. McHardy et al. identified 38 adults who had a high DNA-binding capacity, but negative fluorescent ANA testing (with a rat liver substrate), and the clinical diagnosis of SLE was established for these patients12. In another study, the previously ANA-negative finding, with using mouse liver substrate, in the sera of patients with 
SLE or subacute cutaneous lupus erythematosus was found to be anti-Ro antibody positive by performing enzyme-linked immunosorbent assays ${ }^{13}$. Actually, the increasing use of human epithelial (HEp-2) substrate has increased the sensitivity of ANA assays and as a result, the perceived incidence of ANA-negative SLE has decreased12,14

Another cause of ANA-negative findings is that ANA is present, but its bound in the form of immune complexes. This has been described in five patients with lupus nephritis whose ANAs, which were primarily reactive with DNA, were not detected in the serum by indirect immunofluorescence until the ANAs were dissociated from circulating immune complexes 15. Loss of ANA through the kidney in a patient with profuse proteinuria has been reported as another possibility. In that case, the tests for ANA became positive upon clinical recovery16. However, most ANA-negative patients have persistently negative tests for ANA after a long follow-up period. Technical factors or prozone effects have been described as the possible reasons for this 17 .

SLE is still a disease with significant morbidity and mortality. More recent studies have shown that latest 5 year survival is now nearer $90-95 \%$ and that $70-85 \%$ patients have 10 year survival18. In most studies, patient with renal involvement had poor prognosis compared to patient without it.

CRP usually parallels disease activity in inflammatory conditions as it is an acute phase reactant produced by liver. But SLE is an exception. Patient with active SLE display only modestly elevated or even normal CRP level despite active disease. Marked elevation of CRP in SLE patients indicates infection and serositis ${ }^{19}$. Our patient also had modestly elevated CRP during the admission; this may be due to co-existing infection in this patient as she did not have clinical features of serositis.

Steroids such as Prednisolone have dual therapeutic actions in SLE. It has both antiinflammatory and immunosuppressive actions. It is usually used to treat major organ complications such lupus nephritis and cerebral lupus. Steroid sparing other immunosuppressive agents such as Azathioprine, cyclophosphamide and mycophenolatemofetil should be considered if it is used for long term. When the required daily dose of Prednisolone exceeds $60 \mathrm{mg} /$ day, Intravenous route in the form of Methylprednisolone pulse therapy (30 $\mathrm{mg} / \mathrm{Kg}$, maximum $1 \mathrm{~g} /$ day) should be used. Hydroxychloroquine (HCQ) 200-400 mg/day protects against the disease flare and used to treat dermatological and joint manifestations of SLE.

In conclusion, our patient fulfilled the ACR criteria $r$ without serologic evidence of SLE at presentation. During the follow-up period, the repeated ANA and anti-dsDNA tests were all negative, irrespective of her improving proteinuria, joint and mucocutaneous symptoms. Our patient may be a very rare case of ANA-negative SLE without seroconversion and this suggests that ANA may not be required in the pathogenesis of SLE. ]. If patient fulfil criteria for SLE despite seronegativity, diagnosis should not be delayed as 5-10\% of SLE patient are seronegative 20 .

Auto-antibodies against ribosomal $\mathrm{P}$ proteins appear highly specific for SLE found in 10-15\% patients with SLE; therefore, they can be used as diagnostic marker for the disease. Furthermore, association has been described with particular manifestations of lupus, especially with neuropsychiatric, renal, and hepatic involvements. Anti-P positivity and the titer of anti-P antibodies also fluctuate with clinical disease activity ${ }^{21}$. SLE is nearly always diagnosed months to years after the onset of clinical symptoms and as we have previously shown, even longer after the onset of autoantibodies 22. Antibodies against ribosomal $\mathrm{P}$ frequently develops before clinical SLE diagnosis23.

\section{References}

1. Bagavant H, Deshmukh US, Gaskin F, Fu SM. Lupus glomerulonephritis revisited 2004: autoimmunity and end-organ damage. Scand J Immunol. 2004;60:52-63.

2. Tan EM, Cohen AS, Fries JF, et al. The 1982 
revised criteria for the classification of systemic lupus erythematosus. Arthritis Rheum. 1982;25:1271-1277.

3. Enriquez JL, Rajaraman S, Kalia A, Brouhard $\mathrm{BH}$, Travis LB. Isolated antinuclear antibodynegative lupus nephropathy in young children. ChildNephrol Urol. 1988;9:340-346.

4. Maddison PJ, Provost TT, Reichlin M. Serological findings in patients with "ANA-negative" systemic lupus erythematosus. Medicine. 1981;60:87-94.

5. Koller SR, Johnston CL Jr, Moncure CW. Lupus erythematosus cell preparation-antinuclear factor incongruity. A review of diagnostic tests for systemic lupus erythematosus. Am. J. Clin. Pathol. 66(3), 495-505 (1976).

6. Provost TT, Razzaque A, Maddison PJ, Reichlin M. Antibodies to cytoplasmic antigens in lupus erythematosus: serologic marker for systemic disease. Arthritis Rheum. 1977;20:1457-1463.

7. Berden JHM. Lupus nephritis. Kidney Int. 52, 538-558 (1997).

8. Hochberg MC. Updating the American College of Rheumatology of revised criteria for the classification of systemic lupus erythematosus. Arthritis Rheum. 40(9), 1725 (1997).

9. Petri M, Orbai AM, Alarcons GS et al. Derivation and validation of the systemic lupus international clinic collaborating criteria for systemic lupus erythematosus. Arthritis Rheum. 64(8), 2677-2686 (2012).

10. Maddison PJ. ANA-negative SLE. Clin Rheum Dis. 1982;8:105-119.

11. Provost TT, Reichlin M. Antinuclear antibodynegative systemic lupus erythematosus: I. antiRo (SSA) and anti-La (SSB) antibodies. J Am AcadDermatol. 1981;4:84-89.

12. McHardy KC, Horne C, Rennie J. Antinuclear antibody-negative SLE: how common? J ClinPathol. 1982;35:1118-1121.

13. Reichlin M. ANA negative systemic erythematosus sera revisited serologically. Lupus. 2000;9:116-119

14. Kavanaugh A, Tomar R, Reveille J, Solomon DH, Homburger HA. Guidelines for clinical use of the antinuclear antibody test and tests for specific autoantibodies to nuclear antigens. Arch Pathol Lab Med. 2000;124:71-81.

15. Blomjous FJ, Feltkamp-Vroom TM. Hidden antinuclear antibodies in seronegative systemic lupus erythematosus patients and in NZB and (NZB XN2 W) F1 mice. Eur J Immunol. 1971;1:396-398.

16. Persellin RH, Takeuchi A. Antinuclear antibodynegative systemic lupus erythematosus: loss in body fluids. J Rheumatol. 1980;7:547-550.

17. Linder E, Miettinen A. Prozone effects in indirect immuno-fluorescence. ScandJ Immunol. 1976;5:513-519.

18. Trager J, Ward MM. Mortality and causes of death in systematic lupus erythematosus. Curr. Opin. Rheumatol. 13(5), 345-351 (2001).

19. Honig S, Gorevic P, Weisssmann G. C-reactive protein in systemic lupus erythematous. Arthritis Rheum. 20(5), 1065-1070 (1977).

20.Tsakonas E, Joseph L, Esdalie JM et al. A long term study of hydroxychloroquine withdrawal on exacerbations in systemic lupus erythe matosus. The Canadian Hydroxychloroquine study Group. Lupus 7(2), 80-85 (1997).

21. Kiss E, Shoenfeld Y et al. Are anti-ribosomal P protein antibodies relevant in systemic lupus erythematosus?Clin Rev Allergy Immunol. 2007 Feb;32(1):37-46.

22. Arbuckle MR, McClain MT, Rubertone MV, Scofield RH, Dennis GJ, James JA, Harley JB. Development of autoantibodies before the clinical onset of systemic lupus erythematosus. N Engl J Med. 2003;349:1526-1533.

23. Latisha D. Heinlen, Lauren L. Ritterhouse, Micah T. McClain, Michael P. Keith,Barbara R. Neas,John B. Harley, and Judith A. James. Ribosomal P Autoantibodies are Present Before SLE Onset and are Directed Against non-C Terminal Peptides.J Mol Med (Berl). 2010 Jul; 88(7): 719-727. 